\title{
Keakuratan Kode Diagnosis Penyakit Berdasarkan Icd-10 pada Rekam Medis Rawat Jalan Di Puskesmas
}

\section{Accuracy The Diagnosis Code Based On Icd-10 On An Outpatient Medical Record At Puskesmas}

\author{
Irmawati $\left.{ }^{2}\right)$ \\ Nadelia Nazillahtunnisa1) \\ 1,2) Jurusan Rekam Medis dan Informasi Kesehatan Poltekkes Kemenkes Semarang \\ Jalan Tirto Agung, Pedalangan, Banyumanik \\ Email: irmaedich98@gmail.com
}

\begin{abstract}
An accurate diagnostic code is required to achieve the goal of the classification system for disease diagnosis, one of which is the recording of mortality and morbidity data. Based on preliminary study of 7 samples of medical records in health centers Kagok, get results 2 medical records $(28.57 \%)$ there is an accurate diagnosis and diagnostic code and 4 medical records $(57.14 \%)$ there is an inaccurate diagnosis and diagnosis code, while 1 medical record $(14.29 \%)$ no diagnosis. The purpose of this research is to determine the accuracy of the disease diagnosis code based on ICD-10 in the outpatient medical record in health centers Kagok. This study used a quantitative descriptive research with cross sectional research design. The number of samples on this study was 98 medical records of outpatient patients, taken with a proportional stratified sampling method. The results showed that the medical record was diagnosed as much as 57 medical records $(58 \%)$ while the unwritten diagnosis is as much as 41 medical record $(42 \%)$. From 57 medical records that have been diagnosed, there are only 18 medical records $(32 \%)$ with accurate code and 39 medical records $(68 \%)$ with inaccurate code. The officers of the Diagnosis Code no one has the educational background of the medical record, never participated in special training on coding ICD-10, and did not use the facilities in the health centers in the form of an electronic ICD-10 in giving code diagnosis.
\end{abstract}

Keyword : Code of diagnosis of accuracy; Kagok Puskesmas

\begin{abstract}
Abstrak
Kode diagnosis yang akurat diperlukan untuk mencapai tujuan sistem klasifikasi diagnosis penyakit, salah satunya yaitu pencatatan data mortalitas dan morbiditas. Berdasarkan hasil studi pendahuluan terhadap 7 sampel rekam medis di Puskesmas Kagok didapatkan hasil 2 rekam medis $(28,57 \%)$ terdapat diagnosis dan kode diagnosis yang akurat dan 4 rekam medis $(57,14 \%)$ terdapat diagnosis dan kode diagnosis yang tidak akurat, sedangkan 1 rekam medis $(14,29 \%)$ tidak terdapat diagnosis. Tujuan penelitian ini untuk mengetahui keakuratan kode diagnosis penyakit berdasarkan ICD-10 pada rekam medis rawat jalan di Puseksmas Kagok Kota Semarang. Penelitian ini menggunakan jenis penelitian deskriptif kuantitatif dengan desain penelitian cross sectional. Jumlah sampel pada penelitian ini adalah 98 rekam medis pasien rawat jalan, diambil dengan metode proporsional stratified sampling. Hasil penelitian menunjukkan bahwa rekam medis yang tertulis diagnosisnya sebanyak 57 rekam medis (58\%) sedangkan yang tidak tertulis diagnosisnya sebanyak 41 rekam medis (42\%). Dari 57 rekam medis yang tertulis diagnosisnya, hanya terdapat 18 rekam medis $(32 \%)$ dengan kode akurat dan 39 rekam medis $(68 \%)$ dengan kode tidak akurat. Petugas Pemberi Kode Diagnosis tidak ada yang memiliki latar belakang pendidikan rekam medis, tidak pernah mengikuti pelatihan khusus tentang coding ICD10, dan tidak menggunakan sarana yang ada di puskesmas berupa ICD-10 elektronik dalam memberi kode diagnosis.
\end{abstract}

Kata Kunci : Keakuratan kode diagnosis; Puskesmas Kagok 


\section{Pendahuluan}

Pusat Kesehatan Masyarakat yang selanjutnya disebut Puskesmas adalah fasilitas pelayanan kesehatan yang menyelenggarakan upaya kesehatan masyarakat dan upaya kesehatan perseorangan tingkat pertama, dengan lebih mengutamakan upaya promotif dan preventif, untuk mencapai derajat kesehatan masyarakat yang setinggi tingginya di wilayah kerjanya (Permenkes RI No. 75 Tahun 2014). Puskesmas harus senantiasa meningkatkan mutu pelayanan, sesuai dengan harapan pengguna jasa, melalui peningkatan kualitas kerja. Pelayanan yang bermutu bukan hanya dilihat pada pelayanan medis saja, tetapi juga pada pelayanan penunjang seperti pengelolaan rekam medis.

Rekam medis adalah berkas yang berisi catatan dan dokumen mengenai identitas pasien, hasil pemeriksaan, pengobatan, tindakan, dan pelayanan lainnya yang diterima pasien pada sarana kesehatan, baik rawat jalan maupun rawat inap (Permenkes RI No. 269 Tahun 2008). Rekam Medis memiliki peran dan fungsi yang sangat penting, yaitu sebagai dasar pemeliharaan kesehatan dan pengobatan pasien, bahan pembuktian dalam perkara hukum, bahan untuk keperluan penelitian dan pendidikan, dasar pembayaran biaya pelayanan kesehatan dan terakhir sebagai bahan untuk membuat statistik kesehatan (Hatta, 2012). Oleh karena itu, setiap dokter atau dokter gigi dalam menjalankan praktik kedokteran wajib membuat rekam medis (UU Nomor 29 Tahun 2004).

Perekam Medis mempunyai kewenangan untuk melengkapi rekam medis sesuai kualifikasi pendidikannya yaitu melaksanakan sistem klasifikasi dan kodefikasi penyakit yang berkaitan dengan kesehatan dan tindakan medis sesuai terminologi medis yang benar (Permenkes No. 55 Tahun 2013).

Perekam medis dalam menetapkan kode penyakit dengan tepat sesuai klasifikasi yang diberlakukan di Indonesia menggunakan panduan International Statistical Classification of Diseases and Related Health Problems 10 (ICD-10) tentang penyakit dan tindakan medis dalam pelayanan dan manajemen kesehatan. (Kepmenkes Nomor 377 Tahun 2007).

ICD dipakai untuk mengubah diagnosis penyakit dan masalah kesehatan lain menjadi kode alfa-numerik, bertujuan untuk memudahkan pencatatan data mortalitas dan morbiditas, analisis, interpretasi dan pembandingan sistematis data tersebut antara berbagai wilayah dan jangka waktu (ICD-10 volume 2, 2010). Melihat tujuan sistem klasifikasi penyakit. sarana berupa ICD elektronik. Semarang".

\section{Metode}

diagnosis penyakit tersebut, keakuratan dalam kodefikasi diagnosis penyakit sangat diperlukan untuk menghasilkan data yang akurat dalam mencapai tujuan sistem klasifikasi diagnosis

Puskesmas Kagok Kota Semarang adalah salah satu fasilitas kesehatan tingkat pertama di Kota Semarang yang beralamat di jalan Telomoyo 3, Kecamatan Candisari, Kota Semarang, Jawa Tengah. Merupakan puskesmas non rawat inap yang telah melaksanakan akreditasi pada tahun 2017 dengan hasil madya (Dinkes, 2017). Dalam pelayanan non medis yang salah satunya merupakan pengelolaan rekam medis, terutama dalam melakukan kodefikasi diagnosis penyakit menggunakan pedoman ICD-10, upaya-upaya yang telah dilakukan Puskesmas Kagok Kota Semarang dalam menentukan kode diagnosis penyakit agar akurat adalah dengan penyediaan

Berdasarkan hasil studi pendahuluan yang dilakukan di Puskesmas Kagok Kota Semarang melalui kegiatan observasi dan wawancara kepada petugas pendaftaran yang merupakan satu-satunya petugas dengan latar belakang lulusan DIII Rekam Medis dan Informasi Kesehatan, yang dilakukan pada bulan November tahun 2018 didapatkan hasil sebagai berikut, pengelolaan rekam medis dibantu oleh aplikasi Sistem Informasi Manajemen Puskesmas (SIMPUS). Keakuratan kode diagnosis penyakit terhadap 7 sampel rekam medis yang telah dikode, didapatkan hasil bahwa hanya 3 rekam medis $(42,86 \%)$ yang tertulis diagnosis penyakit dan terdapat kode penyakit, sedangkan 4 rekam medis $(57,14 \%)$ hanya terdapat kode diagnosis. Dari data yang diperoleh peneliti melalui SIMPUS pada 7 sampel rekam medis didapatkan hasil 2 rekam medis $(28,57 \%)$ terdapat diagnosis penyakit dan kode diagnosis penyakit yang akurat dan 4 rekam medis $(57,14 \%)$ terdapat diagnosis penyakit dan kode diagnosis penyakit yang tidak akurat, sedangkan 1 rekam medis $(14,29 \%)$ tidak terdapat diagnosis penyakit dan hanya terdapat kode diagnosis penyakit sehingga tidak dapat dinilai keakuratan kodenya.

Berdasarkan latar belakang di atas, maka peneliti tertarik untuk melakukan penelitian dengan judul "Keakuratan Kode Diagnosis Penyakit Berdasarkan ICD-10 pada Rekam Medis Rawat Jalan di Puskesmas Kagok Kota 
Jenis penelitian ini adalah deskriptif kuantitatif. Desain penelitian ini menggunakan pendekatan cross sectional. Perhitungn sampel dalam penelitian ini menggunakan rumus Slovin dengan hasil 98 rekam medis pasien rawat jalan, adapun pengambilan sampel dilakukan dengan metode proporsional stratified sampling berdasarkan klinik yang ada di Puskesmas Kagok, sehingga diperoleh 61 rekam medis Klinik Umum, 28 rekam medis Klinik Ibu dan Anak, dan 9 rekam medis Klinik Gigi. Metode pengumpulan data menggunakan observasi dan kuesioner. Analisis data menggunakan analisis deskriptif Penyajian data melalui perhitungan persentase untuk menghitung tingkat akurasi kode diagnosis berdasarkan ICD-10 pada rekam medis rawat jalan. Analisis deskriptif digunakan untuk menggambarkan penulisan diagnosis dan karakteristik Petugas Pemberi Kode Diagnosis di Puskesmas Kagok Kota Semarang.

\section{Hasil dan Pembahasan}

Penelitian ini dilakukan pada 98 rekam medis dari 3 klinik yang ada di Puskesmas Kagok yaitu yang terdiri dari 61 rekam medis Kinik Umum, 28 rekam medis Klinik Ibu dan Anak (KIA), dan 9 rekam medis Klinik Gigi.

\section{a. Kelengkapan Penulisan Diagnosis Penyakit}

Tabel 1

Kelengkapan Penulisan Diagnosis Penyakit di Puskesmas Kagok

\begin{tabular}{lccccc}
\hline \multirow{2}{*}{ Klinik } & \multicolumn{3}{l}{ Kategori } & \multicolumn{3}{l}{ Tidak } \\
\cline { 3 - 6 } & $\mathbf{N}$ & \multicolumn{2}{l}{ Lengkap } & \multicolumn{3}{l}{$\begin{array}{l}\text { Lengkap } \\
\end{array}$} & & $\mathrm{n}$ & $\%$ & $\mathrm{n}$ & $\%$ \\
\cline { 3 - 6 } & 6 & 33 & $54 \%$ & 28 & $46 \%$ \\
\hline Umum & 1 & & & & \\
\hline KIA & 2 & 15 & $54 \%$ & 13 & $46 \%$ \\
& 8 & & & & \\
\hline Gigi & 9 & 9 & 100 & 0 & $0 \%$ \\
& & & $\%$ & & \\
\hline Total & 9 & 57 & $58 \%$ & 41 & $42 \%$ \\
& 8 & & & & \\
\hline
\end{tabular}

Sumber : Data Primer Hasil Olahan Checklist

Kelengkapan Penulisan Diagnosis

Tabel 1 menunjukkan bahwa kelengkapan penulisan diagnosis penyakit pada Klinik Gigi keseluruhan terisi penulisan diagnosis, sedangkan pada Klinik Umum dan KIA hanya setengah yang terisi penulisan diagnosis dari masing-masing rekam medis yang diambil sebagai sampel dan dalam dalam penulisan diagnosis terdapat 18 rekam medis yang menggunakan singkatan.

Penjelasan dokter dan bidan menyatakan bahwa tidak menuliskan diagnosis pada semua rekam medis pasien yang datang berkunjung adalah untuk efisiensi dan efektifitas waktu pelayanan. Tidak menuliskan diagnosis pada rekam medis pasien merupakan tindakan yang tidak tepat karena tidak memenuhi ketentuan dalam Permenkes RI Nomor 269 Tahun 2008 tentang isi minimal yang harus tercantum direkam medis rawat jalan yaitu salah satunya adanya penulisan diagnosis. Menggunakan beberapa singkatan untuk menuliskan diagnosis penyakit harus menggunakan standar singkatan yang menjadi pedoman di Puskesmas Kagok, sedangkan di Puskesmas Kagok belum memiliki standar singkatan yang digunakan sebagai pedoman.

\section{b. Keakuratan Kode Diagnosis Penyakit}

Total 98 sampel rekam medis yang dapat dinilai keakuratannya hanya 57 rekam medis (58\%), yang terdiri dari 33 rekam medis Klinik Umum, 15 rekam medis KIA, dan 9 rekam medis Klinik Gigi, sedangkan 41 rekam medis (42\%) tidak dapat dinilai keakuratannya karena tidak terdapat penulisan diagnosis.

\section{Tabel 2}

Rekapitulasi Keakuratan Kode Diagnosis Penyakit di Puskesmas Kagok

\begin{tabular}{cccc}
\hline No & Kategori & n & $\%$ \\
\hline 1. & Akurat & 18 & $32 \%$ \\
\hline 2. & Tidak & 39 & $68 \%$ \\
& Akurat & & \\
\hline & Total & 57 & $100 \%$
\end{tabular}

Sumber : Data Primer Hasil Olahan Checklist Keakuratan Kode Diagnosis Penyakit

Tabel 2 menunjukkan bahwa untuk keseluruhan persentase keakuratan kode diagnosis penyakit dari 3 Klinik yang ada di Puskesmas Kagok pada 57 rekam medis dengan kategori akurat yaitu 18 rekam medis $(32 \%)$ dan untuk kategori tidak akurat yaitu 39 rekam medis $(68 \%)$. 
Kode diagnosis penyakit tidak akurat disebabkan paling banyak karena kurang spesifikasi pada digit ke 4 terdapat pada 20 rekam medis (35\%), penyebab terbanyak kedua yaitu karena salah kode terdapat pada 15 rekam medis (26\%), kemudian penyebab lain yaitu salah pada digit ke 4 terdapat pada 4 rekam medis $(7 \%)$.

Tidak akuratnya kode diagnosis paling banyak disebabkan oleh kurang spesifikasi pada digit ke 4 yaitu sebanyak 20 rekam medis. Sebagai contoh diagnosis Tinea Corporis dikode dalam rekam medis B35. Padahal dalam ICD-10, B35 adalah sub bab penyakit Dermatophytosis yang didalamnya terdapat jenis-jenis penyakit tersebut yang berbeda pada digit ke 4. Selain itu, kode tidak akurat juga disebabkan karena salah kode yaitu pada 15 rekam medis. Sebagai contoh diagnosis Bayi Sehat dikode dalam rekam medis Z00 dengan keterangan pada rekam medis bahwa bayi tersebut diberi imunisasi MR dan PENTA. Padahal dalam ICD-10, Z00 adalah sub bab General examination and investigation of persons without complaint and reported diagnosis, sedangkan untuk imunisasi dengan kombinasi ada pada sub bab Z27, dan kode untuk imunisasi MR yaitu Z27.4 sedangkan untuk imunisasi PENTA yaitu Z27.8. Jika diagnosis yang ditegakkan Bayi Sehat tanpa keterangan atau data penunjang lain dalam rekam medis maka benar kode diagnosisnya adalah pada sub bab Z00, namun apabila terdapat keterangan lain atau data penunjang untuk spesifikasi pemberian kode diagnosis, maka kode diagnosis mengikuti keterangan dan data penunjang di dalam rekam medis seperti keterangan pemberian imunisasi atau tindakan lain pada bayi sehat. Penyebab lain tidak akuratnya kode yaitu salah pada digit ke 4 terdapat pada 4 rekam medis. Sebagai contoh diagnosis Dermatitis alergi dikode L23.8, padahal didalam rekam medis tidak memberikan keterangan penyebab dermatitis alergi tersebut yang seharusnya di kode L23.9 yaitu untuk dermatitis alergi yang unspecified.

Petugas Pemberi Kode Diagnosis di Puskesmas Kagok dalam memberikan kode diagnosis penyakit umumnya berdasarkan hafalan dan berpedoman pada alat bantu yang telah disediakan oleh Puskesmas Kagok berupa selembaran kertas yang berisi daftar kode diagnosis penyakit atau menggunakan internet.

c. Karakteristik Petugas Pemberi Kode Diagnosis

Untuk mengetahui karakteristik Petugas Pemberi Kode Diagnosis dilakukan pengisian kuesioner oleh 6 Petugas Pemberi Kode Diagnosis sebagai responden. Berdasarkan hasil kuesioner, Petugas Pemberi Kode Diagnosis yang setengahnya terdiri dari bidan dan sisanya terdiri dari dokter dengan total 6 orang, tidak ada yang pernah mengikuti pelatihan terkait kompetensi koding. Petugas Pemberi Kode Diagnosis tidak melakukan tahap-tahap coding sesuai dengan panduan yang terdapat pada ICD-10 volume 2 dan lebih memilih menggunakan alat bantu lain yang tidak dapat di ketahui tingkat keakuratannya dari pada menggunakan fasilitas yang ada yaitu ICD-10 manual/elektronik.

Permenkes No 377/Menkes/SK III/2007 Bagian II tentang Kompetensi Perekam Medis, kompetensi klasifikasi dan kodifikasi penyakit merupakan kompetensi pertama dari 7 kompetensi dasar perekam medis, yang menunjukkan pentingnya kemampuan ini bagi seorang ahli madya perekam medis. Pengalaman bekerja yang lama tidak menjamin keakuratan kode diagnosis penyakit bila tidak ditunjang dengan pengetahuan dan keterampilan yang memadai (Lily dan Dyah, 2013). Apabila Petugas Pemberi Kode Diagnosis belum mempunyai kesempatan untuk mendapatkan pendidikan khusus di bidang rekam medis dan informasi kesehatan, maka untuk mendapatkan hasil yang baik, setidaknya Petugas Pemberi Kode Diagnosis memperoleh pelatihan yang 
cukup tentang seluk-beluk pekerjaannya selaku Petugas Pemberi Kode Diagnosis.

\section{Simpulan dan Saran}

\section{a. Simpulan}

Keakuratan kode diagnosis penyakit berdasarkan ICD-10 pada rekam medis rawat jalan di Puskesmas Kagok Kota Semarang belum 100\% akurat, hal ini disebabkan oleh yang selanjutnya akan dijelaskan lebih lanjut sebagai berikut :

1. Kelengkapan penulisan diagnosis penyakit di Puskesmas Kagok yaitu 57 rekam medis (58\%) lengkap dan 41 rekam medis $(42 \%)$ tidak lengkap. Tidak adanya penulisan diagnosis pada rekam medis dikarenakan untuk efisiensi dan efektifitas waktu pelayanan. Serta terdapat penulisan diagnosis menggunakan singkatan yang tidak ada di ICD-10.

2. Keakuratan kode diagnosis penyakit di Puskesmas Kagok dari 57 rekam medis yaitu 18 rekam medis (32\%) dengan kode akurat dan 39 rekam medis (68\%) dengan kode tidak akurat. Penyebab ketidakakuratan kode diagnosis penyakit adalah kurang spesifikasi/salah penulisan pada digit ke 4 dan salah dalam pemberian kode diagnosis atau tidak sesuai dengan ICD-10. Sisa dari total sampel sebesar 41 rekam medis tidak dapat dinilai keakuratan kode diagnosis penyakitnya karena tidak tertulis diagnosis penyakitnya.

3. Karakteristik Petugas Pemberi Kode Diagnosis di Puskesmas Kagok yaitu tidak ada yang memiliki latar belakang pendidikan rekam medis, serta Petugas Pemberi Kode Diagnosis tidak memiliki pelatihan khusus tentang koding ICD-10. Dalam pengalaman bekerja, tidak ada petugas pemberi kode diagnosis yang melakukan tahap-tahap memberi kode diagnosis sesuai dengan prosedur dan lebih memilih menggunakan alat bantu daripada fasilitas ICD-10 yang disediakan di puskesmas.

\section{b. Saran}

1. Pihak Puskesmas sebaiknya melakukan analisis beban kerja, agar setiap tenaga kesehatan dapat memberikan pelayanan secara maksimal seperti salah satunya melengkapi rekam medis.

2. Meningkatkan ketelitian Petugas Pemberi Kode Diagnosis dalam menentukan kode diagnosis penyakit agar lebih spesifik sampai pada digit ke 4 dengan mengikuti pelatihan mengenai kompetensi coding.

3. Petugas Pemberi Kode Diagnosis di Puskesmas Kagok sebaiknya memiliki pengetahuan tentang rekam medis, mengikutsertakan Petugas Pemberi Kode Diagnosis untuk ikut dalam pelatihan yang berkaitan dengan kode diagnosis penyakit menggunakan ICD. Serta menggunakan ICD-10 yang ada untuk menetapkan kode diagnosis penyakit.

\section{Ucapan Terima Kasih}

Dalam penyusunan Karya Tulis Ilmiah ini, penulis banyak mendapatkan saran, kritik, bimbingan serta motivasi dari banyak pihak, yang menjadikan penulis dapat menyususn Karya Tulis Ilmiah ini dengan baik dan dapat dipertanggungjawabkan. Oleh karena itu, dengan segala hormat dan kerendahan hati, perkenankan penulis mengucapkan terimakasih untuk seluruh pihak yang terlibat dalam penyusunan Karya Tulis Ilmiah ini.

\section{Daftar Pustaka}

Depkes RI. 2006. Pedoman Penyelenggaraan dan Prosedur Rekam Medis Rumah Sakit di Indonesia. Jakarta: Depkes RI

Gemala Hatta. 2008. Pedoman Manajemen Informasi Kesehatan di Sarana Pelayanan Kesehatan. Edisi revisi 2. Jakarta : Penerbit Universitas Indonesia.

Hariandja, Marihot Tua Efendi. 2002. Manajemen Sumber Daya Manusia : Pengadaan, Pengembangan, Pengkompensasian, dan Peningkatan Produktivitas Pegawai. Jakarta : Grasindo.

Hatta. G R., (2009), Pedoman Manajemen Informasi Kesehatan Di Sarana Pelayanan 
Kesehatan. Jakarta: Universitas Indonesia (UI Press)

Kresnowati Lily, Ernawati D. 2013. Analisis Faktor-Faktor yang Mempengaruhi Koding Diagnosis dan Prosedur Medis pada Dokumen Rekam Medis di Rumah Sakit Kota Semarang. Laporan Akhir Penelitian Dosen Pemula

Lisa, Herlinawati. (2015). Keakuratan Kode Penyakit Di Puskesmas Srondol Periode Triwulan II Tahun 2015. Semarang : Program Studi Rekam Medis dan Informasi Kesehatan, Fakultas Ilmu Kesehatan UDINUS Semarang.

Notoatmodjo, Soekidjo. 2010. Metodologi Penelitian Kesehatan. Jakarta : Rineka Cipta

Nursalim, Mochamad. 2001. Psikologi Pendidikan. Surabaya : Unesa University Press.

Putri, Annisa Amanda. 2018. Analisis Keakuratan Kode Diagnosis Penyakit Berdasarkan ICD-10 Dalam Rekam Medis Rawat Jalan Di Puskesmas Tlogosari Kulon Kota Semarang. Semarang : Program Studi DIII Rekam Medis dan Informasi Kesehatan, Poltekkes Kemenkes Semarang World Health Organization. 2004. International Statistical Classification of Disease and Related Health Problem Tenth Revision (ICD-10) Volume 1. Geneva:WHO 2004. International Statistical Classification of Disease and Related Health Problem Tenth Revision (ICD-10) Volume 2. Geneva:WHO
2004. International Statistical Classification of Disease and Related Health Problem Tenth Revision (ICD-10) Volume 3. Geneva:WHO 2004. Klasifikasi Statistik Internasional Mengenai Penyakit Dan Masalah Kesehatan Terkait (ICD-10) Cara Penggunaan. Erkadius. 2012. Padang: APIKES IRIS

Undang-Undang Republik Indonesia Nomor 20 Tahun 2003 tentang Sistem Pendidikan Nasional

Undang-Undang Republik Indonesia Nomor 29 tahun 2004 tentang Praktek Kedokteran. Jakarta : Republik Indonesia

Permenpan Republik Indonesia No. 30 tahun 2013 tentang Jabatan Fungsional Perekam Medis dan Angka Kreditnya. Jakarta : Republik Indonesia

Peraturan Menteri Kesehatan (PERMENKES) Republik Indonesia Nomor 269/MENKES/PER/III/2008 tentang Rekam Medis. Jakarta : Republik Indonesia

Peraturan Menteri Kesehatan (PERMENKES) Republik Indonesia Nomor 55 tahun 2013 tentang Penyelenggaraan Pekerjaan Rekam Medis.Jakarta : Republik Indonesia

Peraturan Menteri Kesehatan (PERMENKES) Republik Indonesia Nomor 75 tahun 2014 tentang Pusat Kesehatan Masyarakat. Jakarta : Republik Indonesia

Keputusan Menteri Kesehatan (KEPMENKES) Republik Indonesia Nomor 377 tahun 2007 tentang Standar Profesi Perekam Medis dan Informasi Kesehatan. Jakarta : Republik Indonesia 